\title{
Computing in the real world
}

\section{Tokyo, Munich \& London}

OfFICIALS of Japan's Ministry of International Trade and Industry (MITI) have been touring the capitals of Europe trying to drum up international support for a massive government-industry project to develop next-generation parallel computers.

The Real World Computing project is MITI's follow-up to the once-feared but long-since-forgotten fifth-generation computer project. This time, rather than setting their sights on one particular type of parallel computer, MITI officials intend to take a multi-pronged approach looking at neural networks and optical computers, as well as massively parallel machines. And, unlike the fifth-generation project, which is primarily a domestic affair, MITI hopes to invest as much as 20 per cent of the proposed $¥ 100,000$-million (\$750-million) budget for the ten-year project overseas.

Last month, MITI officials visited Brussels, Bonn, Paris and London inviting European researchers to join the programme. Earlier attempts to win the support of the United States were not very successful: the United States intends to participate only in a optoelectronic collaboration (see accompanying story), an area in which Japan is strong and has much to offer.

One idea being proposed by MITI is to establish a high-capacity computer link between several laboratories in Europe and the new Real World Computing institute that will be set up in Tsukuba science city.

Although the reception of the MITI delegation in some countries was fairly cool, French and German researchers are quite enthusiastic about the Japanese project. Wolfgang Giloi of the German National Research Centre for Computer Science (GMD) in Berlin has offered to become a full partner in the project, and GMD has volunteered to host one of three remote laboratories connected by computer link to Japan that the Japanese wish to finance in Europe.

The French are more cautious. Laurent Kott, deputy director of the National Institute for Research in Computer Science and Automation, agrees that the project offers an important opportunity, but he says the exact nature of the scientific opportunities is "vague". Ian Watson of the University of Manchester notes that "the Japanese seemed to be [taken aback] by the fact that they got questioned by UK academics on the concrete goals of the project". Vagueness is characteristic of the early stages of Japanese projects, when a consensus on the direction is still being built. "It requires a certain leap of faith to join a Japanese national project" says the science officer of one European embassy in Tokyo.

But the Japanese are making efforts to be more in line with the European approach, and Japan's laws have recently been re-written to allow participants in national projects to hold up to 50 per cent of patent rights. In the past, the government held all rights.

Nevertheless, some European researchers hesitate to join. Paul Refenes, a computer scientist at University College, London, says that Britain is likely to be "wary" of collaborating in areas where it is ahead of Japan, such as massively parallel computing. Collaborations in neural networking, where Europe and Japan are in equal states of advance, are more likely to be considered, he says.

The German and French ministries of research are trying to define their positions on the project at both a research and a political level, and France is lobbying for a common European position to be adopted.

In Japan, most of the major electronics companies, such as Hitachi, NEC, Toshiba and Fujitsu are expected to join. "Surprisingly", steel companies have also shown great interest in recent workshops on the project, says Yoshiki Mikami, director of MITI's Information, Computer and Communications Policy Office. A few Japanese subsidiaries of foreign companies, such as DEC of the United States, have also shown interest, but Mikami expects foreign participation to be confined "mainly to academics".

\section{David Swinbanks, Alison Abbott} \& Ian Mundell

\section{White House welcomes Japanese offer to help industry.}

THE US government is considering a proposal from Japan to give US researchers access to the Japanese industry's state-of-theart optoelectronic components. Officials hope that a collabora tion with Japan's Real World Computing project will unite the struggling US optoelectronics industry at a cost of just a few million dollars a year to the United States.

The arrangement, although favourable to US researchers, is not quite as one-sided as it sounds. Neither country will actually give up any proprietary technology. Instead, each country would build advanced components for the other, or swap specifica tions so that collaborating researchers can include previously unavailable components in their own optoelectronic devices.

As currently proposed, the collaboration would be based on the 'broker' principle, similar to that now being practised in a US/Japanese semiconductor collaboration known as MOSIS. In that model, a third party matches an inventory of potential users of state-of-the-art devices in one country with manufacturing facilities in the second country. In theory, no proprietary manufacturing techniques are needed transferred, but everyone gets access to the technology.

Under this system, a US researcher could obtain the specification of, for example, a laser available only in Japan. The researcher could then design a device around the specification, and either ship it to Japan to have the laser added, or request the part itself. Either way, the Japanese company need not share any of the proprietary details of how it makes the laser, or how it works.

Eugene Wong, associate director for physical sciences and engineering at the White House Office of Science and Technot ogy Policy, which is coordinating the US side of the negotiations, says that the method is a way to "use technology without acquiring technology" - just the right combination of what the US industry needs and what Japan is willing to give up. The US optoelectronics community is still fragmented, he says, and lacks a critical mass to sustain itself. The lure of Japanese technology could generate the type of collaboration between US industry and the academic community that is needed.

Before any agreement can be signed, however, the United States and Japan will have to resolve some philosophical differences. In the Japanese view, the goal of the collaboration is more joint research. That is because Japan, thanks in part to its camera industry, has a wide lead over the United States in optics technology. In keeping with their research emphasis, Japanese officials believe that the broker need not be an expert - in fact, the less the broker knows, the more willing the parties will be to cooperate without fear of exposing secrets.

Under the US model, however, brokers must understand the technology well enough to know what not to divulge to the other side. Wong suggests a non-competitive, yet informed, third party, such as a US university.

The two views may be reconciled during a six-month feasibility study involving half a dozen US agencies and industry groups, including the Optoelectronics Industry Development Association, a one-year-old group headed by Arpad Bergh of Bell Communications Research. Bergh expects little US opposition to the proposal. But it remains to be seen whether Japan wants US participation in its Real World project badly enough to accept the US view of a model collaboration. 